\title{
Scanning electron microscope study of herpes simplex virus experimental disciform keratitis
}

\author{
ROSE MARIE NAGY, ROSEMARY C. MCFALL, THEODORE W. SERY, \\ BARBARA T. NAGLE, AND LOLLY M. MCGREEVY \\ From the Wills Eye Research Institute and Philadelphia College of Osteopathic Medicine, Philadelphia, USA
}

SUMMARY Scanning electron microscopy of the endothelium of experimental disciform ker tis revealed corneal endothelial changes which distinguished disciform oedema from the re progressive stages of disciform keratitis. The endothelium of corneas with disciform oedema , re wholly intact and characterised by subtle morphological alterations. In contrast, the more progressive stages of disciform keratitis were characterised by massive destruction and denudation of the endothelium. The significance of these observations is discussed.

The exact aetiology of disciform oedema, a discrete stage of disciform keratitis, remains unknown. Clinical specimens obtained from candidates for corneal transplant show chronic deep stromal herpes disease (Dawson et al., 1968). Disciform keratitis is induced in animals by severe corneal infections, hyperimmunisation procedures, or both (Williams et al., 1965; Swyers et al., 1967; Meyers and Pettit, 1973; Hoffman et al., 1976). As a result clinical and experimental specimens include a variety of immunological and infectious complications. It has been reported that the endothelium of these corneas shows several morphological changes. These alterations may include cellular oedema, giant cell formation, derangement of cells, distinct viral plaques, peripheral endothelial denudation, and more pronounced central endothelial damage (Hogan et al., 1963; Irvine and Kimura, 1967; Oh, 1970).

The experimental disciform keratitis model described by Sery et al. (1972) was used throughout this study. This unique model permits separation of discrete disciform oedema from the more progressive stages of the disease. The purpose of this scanning electron microscopic (SEM) investigation was to observe the endothelial topography of corneas during the discrete stage of disciform oedema. As a comparison corneal specimens from eyes with more progressive stages of disciform keratitis as well as injured uninfected controls were observed.

Address for reprints: Dr R. M. Nagy, Wills Eye Research Institute, 1601 Spring Garden Street, Philadelphia, Pa. 19130, USA

\section{Materials and methods}

Virus propagation. Rabbit corneal fibroblast cultures established in our laboratory were grown in Eagle's minimal essential medium (MEM) supplemented with $10 \%$ heat-inactivated foetal calf serum and antibiotics. When confluent, the monolayer cultures were washed 3 times with phosphate buffered saline (pH 7.2) to eliminate most of the foetal calf serum. The cultures were then seeded with the H-4 strain of herpes simplex virus at a multiplicity of infection of 4 to 7 virus particles per cell. Medium 199 without serum was added for virus propagation. After 40 hours of incubation at $34^{\circ} \mathrm{C}$ the virus suspensions were harvested, titered, and diluted in Medium 199 to a final concentration of 10000 virus particles per millilitre.

Animal inoculation. Normal grey chinchilla rabbits weighing 2 to $2.5 \mathrm{~kg}$ were used in this study. The corneas were anaesthetised by topical administration of $1 \%$ proparacaine hydrochloride (Ophthaine). Both eyes of 10 test animals received intrastromal injections of $200 \mathrm{H}-4$ virus particles in $0.02 \mathrm{ml}$ of Medium 199, while both eyes of 5 control rabbits received an intrastromal injection of $0.02 \mathrm{ml}$ of Medium 199 only.

Preparation of whole corneas for SEM. Slit-lamp examination of virus-inoculated corneas verified the presence of disciform keratitis. Within 1 to 2 days after the occurrence of disease the rabbits were killed with an overdose of sodium pentobarbital. In addition control rabbits were killed at various times. After enucleation all corneas were excised, leaving a 1-mm scleral ring, and fixed for 3 hours in 838 


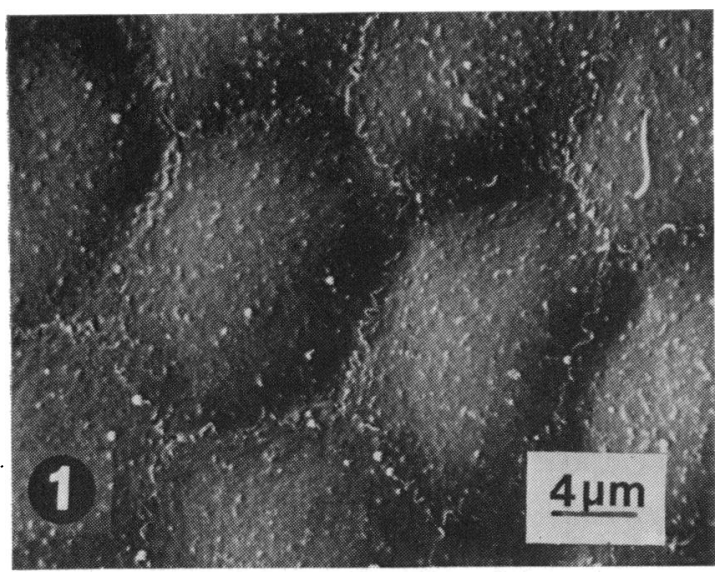

Fig. 1 Normal mosaic-like pattern of rabbit corneal endothelium. Cell borders are well defined, while small finger-like microvilli are evenly distributed over the cell surfaces $(\times 1900)$

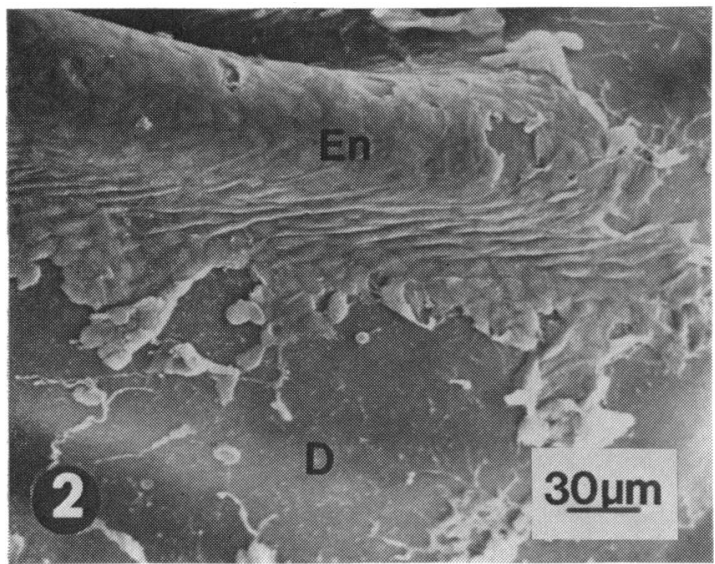

Fig. 2 Endothelium (EN) of a rabbit cornea which presented with a dendritic lesion and disciform oedema is denuded, exposing large areas of Descemet's membrane (D)

cold $\left(4^{\circ} \mathrm{C}\right) 2 \cdot 7 \%$ glutaraldehyde buffered to $\mathrm{pH} 7 \cdot 2$ with $0 \cdot 2 \mathrm{M}$ sodium cacodylate- $\mathrm{HCl}$.

After primary fixation the corneas were washed twice in cacodylate- $\mathrm{HCl}$ buffer, post-fixed for 1 hour in cold $\left(4^{\circ} \mathrm{C}\right) 0.5 \%$ osmium tetroxide buffered to pH 7.2 with $0.2 \mathrm{M}$ cacodylate- $\mathrm{HCl}$, and washed twice in buffer for 215 -minute intervals. The corneas were then dehydrated at 15 -minute intervals in graded ethanol $(30,50,70,90,100 \%)$, ethanolamyl acetate $(50 / 50 \%)$, and amyl acetate $(100 \%)$. While submerged in amyl acetate the specimens were processed through a Sorvall critical point drying apparatus using $\mathrm{CO}_{2}$ according to the technique described by Anderson (1951). After drying the corneas were mounted (endothelial side up) on stubs, coated with carbon and gold, and examined at $25 \mathrm{kV}$ in a Joel JSM $50-\mathrm{A}$ scanning electron microscope with the specimen tilted at $30^{\circ}$.

\section{Results}

Rabbit corneas injected intrastromally with a low dose of the highly invasive $\mathrm{H}-4$ strain of herpes simplex virus present a classical disciform keratatis

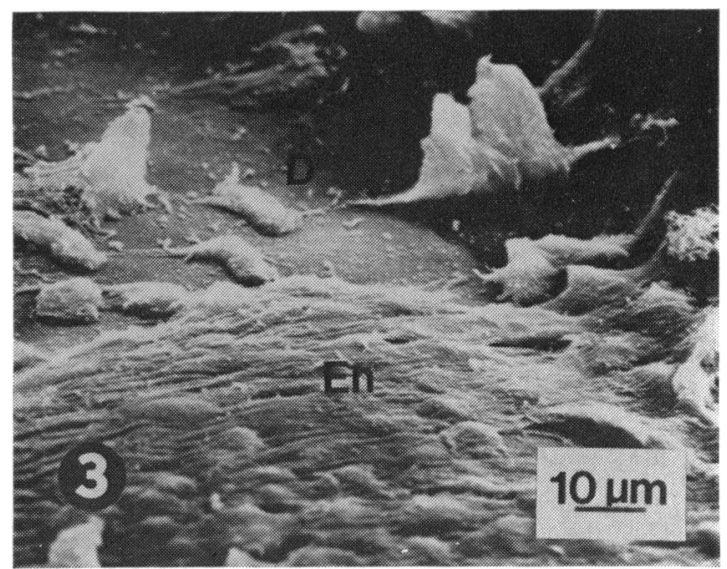

Fig. 3 Endothelium of a cornea which presented with benign disciform keratitis showed large areas of peripheral denudation with exposure of Descemet's membrane (D). The endothelium (EN), which remained intact, appears abnormal $(\times 630)$



Fig. 4 The endothelium of a cornea which presented with a small dendritic lesion and subsequent disciform oedema showed this centrally located area of irregular topography. When compared to normal endothelium (Fig. 1) cell surfaces appear active, with an exaggerated number of microvilli. In addition, cell borders are ill defined $(\times 1000)$ 
with or without complicating dendritic keratitis. This experimental disease displays features similar to the clinical syndrome described in man. In its most benign form symptoms of the experimental disciform keratitis include stromal oedema and haze, while moderate stages show diffuse oedema, granular infiltrates, and anterior uveitis. In benign and moderate disease the epithelium generally remains intact. In the more severe form of the disease stromal necrosis, neovascularisation, and surface epithelial lesions are evident.

The corneal endothelium from 3 groups of rabbits was evaluated for topographical changes. The first group of animals included those which received an instrastromal injection of virus and, when killed,

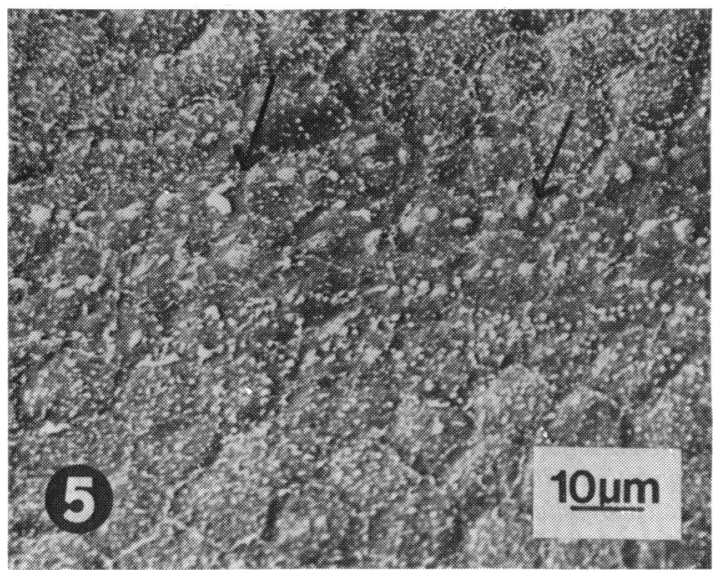

Fig. 5 The endothelium of a cornea with benign disciform keratitis showed a subtle area of abnormal topography observed as a line (arrows) in the centre of this micrograph $(\times 630)$

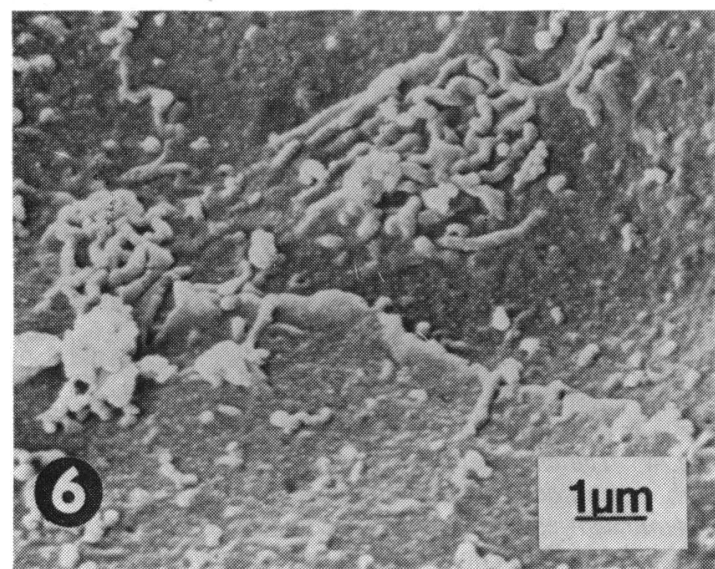

Fig. 6 A high-magnification SEM view showed this line to be formed by the aggregation or agglutination of microvilli $(\times 6300)$



Fig. 7 The normal topography of the endothelium of a cornea which presented with benign disciform keratitis is interrupted by irregularly shaped and enlarged cells (arrow) $(\times 630)$

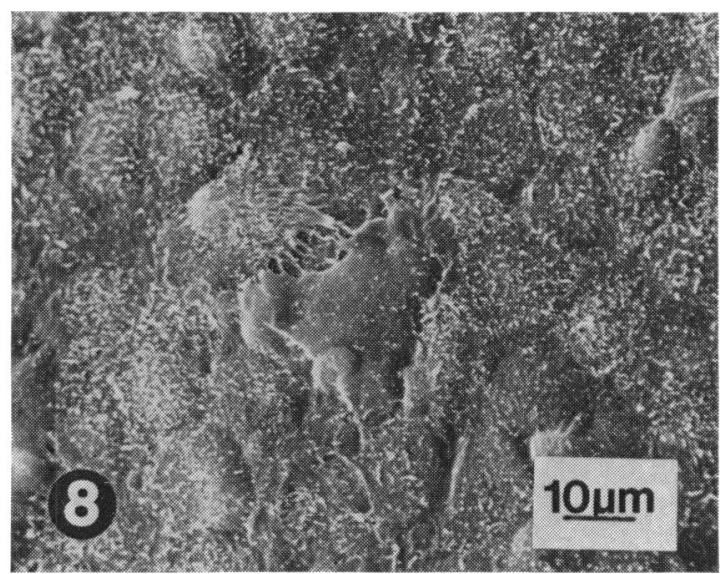

Fig. 8 In addition the same cornea (Fig. 7) showed endothelial 'giant' cell formation as observed in the centre of this photomicrograph. An increased number of microvilli is also evident $(\times 630)$

displayed disciform keratitis as well as small surface dendritic lesions. The second group of rabbits received an intrastromal injection of virus but, when killed, displayed disciform oedema with no prior episode of dendritic keratitis. Finally, the third group of rabbits received an intrastromal injection of Medium 199, and therefore served as noninfected, traumatised controls.

All corneas from the control group showed the normal mosaic-like pattern of endothelium (Fig. 1). Cell borders were well defined, and relatively few microvilli were evenly distributed over the smooth surfaces of the cells.

With rabbits displaying progressive stages of 


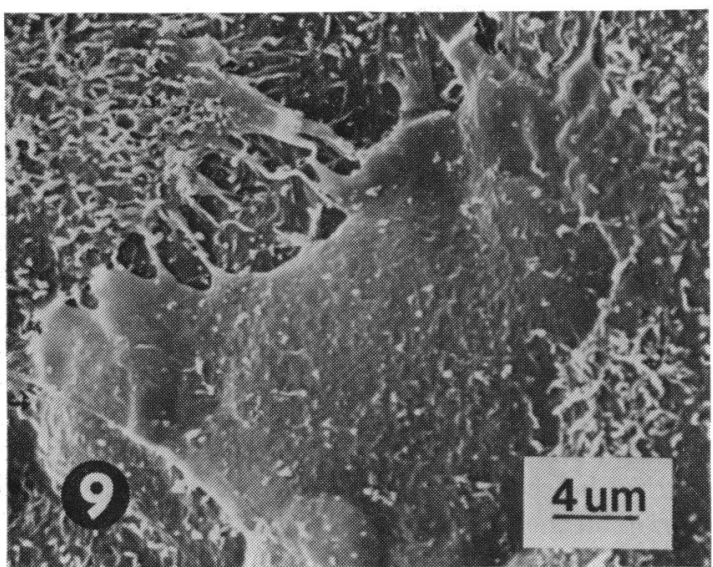

Fig. 9 A higher magnification of Fig. 8. This giant cell is either a single oedematous cell or the fusion of cells. Multinuclear giant cells are observed in herpes virus infected corneal fibroblasts in vitro $(\times 1900)$

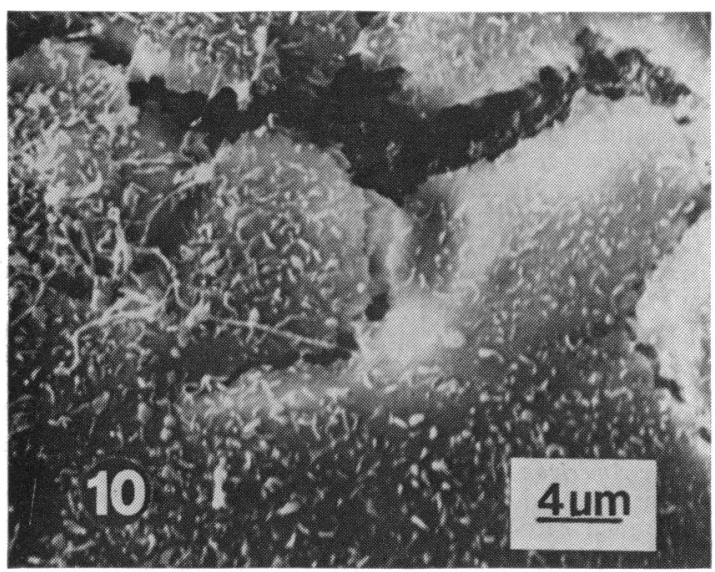

Fig. 10 The endothelium of a cornea with benign disciform kerutitis showed these large irregular cells. The junctions between these cells have broken down $(\times 1900)$

disciform keratitis (those corneas showing concurrent small dendritic lesions) massive destruction and denudation of the endothelium was evident (Fig. 2). Endothelial damage within this group was generally confined to the periphery (Fig. 3). However, we were able to correlate the severity of anterior uveitis with progressive central endothelial damage. Although some areas of the endothelium remained intact, certain morphological alterations were evident. These included loss of defined cell boundaries and more active cell surfaces expressed by the significant increase in the number and length of microvilli (Fig. 4). In addition to the morphological changes all endothelium within this group showed a large number of inflammatory cells at the limbus.

The endothelial alteration associated with benign disciform keratitis is more subtle. Wholly intact endothelium had cells with extraordinary surface activity in the form of increased number and the agglutination of microvilli (Figs. 5, 6). In addition cellular oedema (Fig. 7) with concomitant openingup of intercellular junctions (Figs. 10,11), and giant cell formation (Figs. 8, 9) was evident. Within this group 1 animal (both corneas) had endothelium

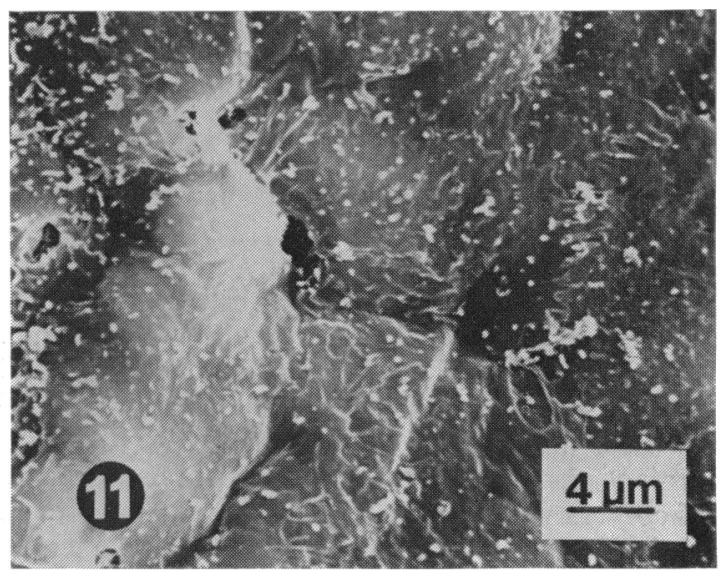

Fig. 11 This photomicrograph of a benign disciform cornea shows oedematous, irregularly shaped endothelial cells. Cell borders are ill defined, while gaps appear between some of the cells $(\times 1900)$

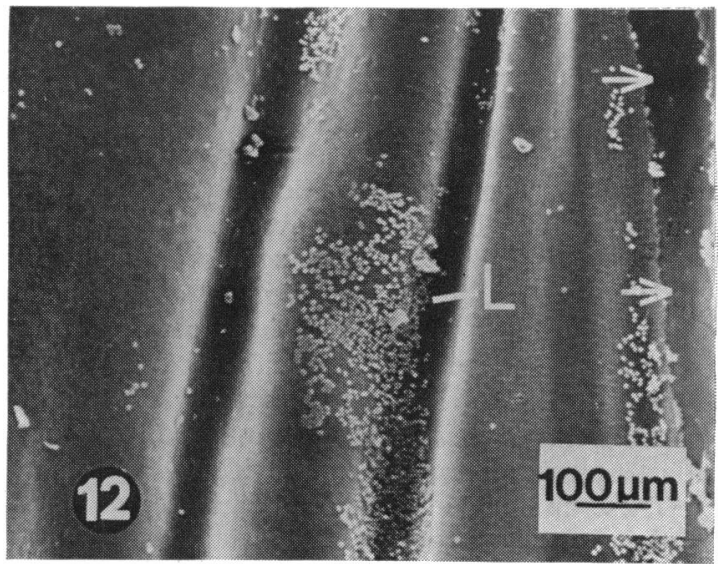

Fig. 12 This photomicrograph of the endothelium of a cornea with benign disciform keratitis shows massive invasion of leucocytes ( $L$ ). In addition large numbers of leucocytes were also observed at the limbus. The endothelium has remained intact except at the periphery, where large denuded areas expose Descemet's membrane (arrows) ( $\times 63)$ 
with peripheral denudation (Figs. 3, 12). In addition a massive influx of inflammatory cells was evident at the limbus (Fig. 12).

\section{Discussion}

SEM of the corneal endothelium from animals with experimental progressive disciform keratitis showed changes such as cellular oedema, cell derangement, and peripheral denudation. These observations confirm the findings of Irvine and Kimura (1967) and Oh (1970). In contrast we observed that peripheral denudation was accompanied by an influx of inflammatory cells. In addition we are able to correlate centralised endothelial damage with the severity of the disciform keratitis and anterior uveitis.

Our SEM study reveals that benign experimental disciform keratitis is characterised by an intact endothelium, which is modified by subtle and diffuse morphological changes. These changes correlate with the appearance of deep stromal corneal oedema. Oh (1970) described the relationship of deep corneal opacity and diffuse endothelial lesions after anterior chamber inoculation of $\mathrm{HSV}$. He also observed distinct plaques of viral origin on the endothelium of corneas with or without opacities. In the present study distinct endothelial plaques are not apparent at any stage of $\mathrm{HSV}$ induced disciform keratitis. Moreover, we could not confirm the report by Irvine and Kimura (1967) that the central endothelium is most severely damaged beneath the area of stromal oedema.

Histological evaluation of the intrastromal lowdose virus model of disciform keratitis has shown the appearance of inflammatory cell types in diseased corneas (Sery and Nagy, 1977). Mononuclear leucocytes are the most consistently observed inflammatory cell type, while polymorphonuclear leucocytes may be scarce or absent. When draining lymph node cells are tested against specific HSV antigens via blast transformation assays, no significant response to specific HSV antigens is evident during the discrete stage of disciform oedema (Nagy et al., 1975). However, as the severity of disciform keratitis increases, specific HSV induced lymphocyte blast transformation becomes evident.

These findings, in addition to the present investigation, suggest that the early stage of disciform keratitis may be composed of two distinct phases. The initial phase is non-specific; the corneal endothelium remains intact, but characteristic subtle and diffuse lesions are evident. Although leucocytes infiltrate the corneal stroma, inflammatory cells are noticeably absent from the anterior chamber. Regional draining lymph node cells tested at this time show no reactivity to specific HSV antigens. The second phase of early disciform keratitis is accompanied by an acute inflammatory reaction within the anterior chamber. Peripheral endothelial denudation is observed and may become more progressive toward the centre. This second phase is specific, that is, there is evidence of HSV antigen specific cell-mediated immunity by the lymphocytes of regional draining lymph nodes.

Endothelial destruction during disciform keratitis may be the result of direct viral invasion, lymphocytemediated cytotoxicity, or other immune mechanisms. Further investigations are at present under way to clarify the relative role of viral and immunological factors in the early stage of disciform keratitis.

This project was supported by the Eye Foundation of Delaware Valley Inc., grant EY00195 awarded by the National Eye Institute, and grant RR05510 of the National Institutes of Health.

\section{References}

Anderson, T. F. (1951). Techniques for the preservation of three-dimensional structures in preparing specimens for electron microscopy. Transactions of the New York Academy of Sciences, 13, 130-133.

Dawson, C., Togni, B., and Moore, T. E. (1968). Structural changes in chronic herpetic keratitis. Archives of Ophthalmology, 79, 740-747.

Hoffman, F., Harnisch, J. P., Dumitrescu, L., Haase, J., and Museteanu, Cr. (1976). Herpes simplex corneae: a scanning and transmission electron microscopic study of the rabbit eye. In The Structure of the Eye III, pp. 77-86. Edited by Yamada and Mishima.

Hogan, M. J., Kimura, S. J., and Thygeson, P. (1963). Pathology of herpes simplex keratouveitis. Transactions of the American Ophthalmological Society, 61, 75-99.

Irvine, A. R., and Kimura, S. J. (1967). Experimental stromal herpes simplex keratitis in rabbits. Transactions of the American Ophthalmological Society, 65, 189-210.

Meyers, R. L., and Pettit, T. H. (1973). Corneal immune response to herpes simplex virus antigens. Journal of Immunology, 110, 1575-1590.

Nagy, R. M., McFall, R., and Sery, T. W. (1975). The relationship of cell mediated immunity to a classical herpes simplex disciform keratitis. The Association for Research In Vision and Ophthalmology, Spring Meeting, Sarasota, Florida.

Oh, J. O. (1970). Endothelial lesions of rabbit cornea produced by herpes simplex virus. Investigative Ophthalmology, 9, 196-205.

Sery, T. W., Nagy, R. M., and Nazario, R. (1972). Experimental disciform keratitis. 3. Virus infectivity versus hypersensitivity in herpesvirus stromal disease. Ophthalmic Research, 4, 137-144.

Sery, T. W., and Nagy, R. M. (1977). Cellular reaction in experimental herpetic disciform keratitis. American Journal of Ophthalmology, 84, 675-680.

Swyers, J. S., Lausch, R. N., and Kaufman, H. E. (1967). Corneal hypersensitivity to herpes simplex. British Journal of Ophthalmology, 51, 843-846.

Williams, L. E., Nesburn, A. B., and Kaufman, H. E. (1965). Experimental induction of disciform keratitis. Archives of Ophthalmology, 73, 112-114. 